\title{
Consideration on the Bilingual Teaching of Computer Courses in Higher Vocational Colleges
}

\author{
Jiangtao GENG ${ }^{1}$, \\ ${ }^{1}$ Guangzhou International Economics College, \\ Guangzhou 510540, China
}

\begin{abstract}
To implement bilingual teaching is an inevitable choice of higher vocational colleges to be geared to international standards and improve their professional competitive advantages. The practice of bilingual teaching of computer courses has been implemented by the School of Information, Guangzhou International Economics College concerning foreign affairs or foreign nationals. In this paper, the actual problems in the bilingual teaching of computer programming course are emphatically analyzed, and then the related countermeasures are introduced from bilingual course selection, improving students' enthusiasm with MOOC and flipped classroom, step-by-step bilingual teaching model, and practice teaching material selection, aiming to promote the development of bilingual teaching of computer courses in higher vocational colleges and the competitive power of students at workplace.
\end{abstract}

Keywords: Higher Vocational Teaching Research; Bilingual Teaching; Problems and Countermeasures

\section{Introduction}

After the requirements of the Ministry of Education for the implementation of the bilingual teaching in the field of high and new technologies such as information technology were released, bilingual teaching has been vigorously developed in the computer-related course teaching in China's colleges and universities. Guangzhou International Economics College, as higher vocational college

\author{
Xiaobo XIONG ${ }^{1}$ \\ ${ }^{1}$ Guangzhou International Economics College, \\ Guangzhou 510540, China
}

with typical foreign-related characteristics, has implemented the bilingual teaching of object-oriented $\mathrm{C}++$ programming course in the School of Information. After a year of bilingual teaching practice, certain teaching achievements have been made, but education workers are required to rethink about various problems in the teaching and explore a future development direction. Combined with the practice of $\mathrm{C}++$ language bilingual teaching in the School of Information, these problems are discussed in this paper.

\section{Practical problems in the current bilingual teaching}

The basic situation of the bilingual teaching course offered in the School of Information in two semesters is first introduced, and then the existing problems are analyzed.

\subsection{The basic situation of the establishment of bilingual teaching course}

At the second semester of academic years 2013-2014, 90 computer application technology students (oriented at software engineer) in two classes of the School of Information were chosen. The bilingual teaching method was applied to the teaching of the object-oriented C++ programming course, offered with 108 class hours at the second semester of the first academic year, and simultaneously the examination reform was combined together, thus promoting the implementation of the reform of the bilingual teaching, achieving a good teaching effect, and 
practically improving the actual programming ability of students.

At the second semester of academic years 2014-2015, 65 computer network technology students (oriented at network engineer) in two classes of the School of Information were chosen. The bilingual teaching method was also applied to the teaching of the object-oriented $\mathrm{C}++$ programming course, offered with 108 class hours at the second semester of the second academic year. However, the actual teaching effect was not ideal though the same teaching model was used. This problem is analyzed in the following.

\subsection{An analysis of the problems in the bilingual teaching}

On the surface, these students were in the School of Information and admitted in the same year (i.e. 2013), and also teaching contents and class hours were identical, but the teaching effects were greatly different and there were mainly four reasons for this problem after a careful analysis.

(1) The bilingual teaching of $\mathrm{C}++$ programming course was difficult for computer network technology students to comprehend

Computer programming is a compulsory course in the computer science major of higher vocational colleges, but distinct in difficult and easy knowledge points. In the computer world, it is generally believed that $\mathrm{C}++$ language is the hardest programming language to learn because of complex architecture, indicator, memory management, and the processing of multiple inheritances.

(2) The enthusiasm of these students in two majors was greatly different

Students are the main bodies of learning, and thus bilingual teaching is difficult to obtain a good effect if there are no students to actively participate in. In the two classes majoring in computer application technology, the learning styles were good, and also all of the students were freshmen when the bilingual course was being offered so that their learning enthusiasm was higher. Students' active before-class preview and after-class review for course contents played an important role in the learning effect of the bilingual course. There was a typical example to illustrate this problem: the female students in class two (computer application technology) had not slept all night to accomplish the practical training assignments required to be submitted on the second day, making the teacher deeply touched. However, the class style and learning style of the students majoring in computer network were greatly different from those of the students majoring computer application technology, and the bilingual course was offered to them in the second academic year, thus making their learning enthusiasm greatly discounted.

(3) Deep cross-teaching model was always used by teachers and the students' English was overestimated

The teaching model was divided into three types according to the use frequency of native language and foreign language in the classroom: the term guiding model, in which Chinese explanation was primarily used, and English terms were in mixed use; the cross-teaching model, in which Chinese and English were used alternately according to teaching contents; the completely penetrating model, in which English was entirely used in teaching, and questions and assignments were finished in English.

(4) The help of the selection of practical training materials was limited for higher vocational students

The teaching material Bilingual $\mathrm{C}++$ Programming, which is compiled according to the layout of both Chinese and English and the bilingual teaching demonstration course standards required by the Ministry of Education, was used in the School of Information as the major textbook. It is a rarely excellent bilingual teaching material, but demanding it to completely accord with the requirement of the case teaching and practical teaching in higher vocational colleges may be difficult. Therefore, 
good training materials are needed to support the teaching material.

In the process of carrying out the bilingual teaching, the textbooks supporting the national high quality courses and the experiment instructional books were used as the practice teaching materials. The knowledge point of each part was summarized and also specific experimental instructions were available in the experiment instructional books, but this kind of teaching materials was not geared to the needs of higher vocational students and could not highlight the practicability required in the teaching materials of higher vocational education, and also did not play a role in guiding the practice in the case teaching process. Therefore, the help of these materials for students was rather limited. When students were difficult to comprehend the theory in the major teaching material and turned to seek a help from practice teaching cases, this kind of materials was often powerless, finally making the effect of the bilingual teaching affected objectively.

\section{Countermeasures to solve the problems in the bilingual teaching}

According to the above mentioned problems in the bilingual teaching, the following countermeasures are proposed after carefully thinking.

\subsection{Choosing basic and practical courses as bilingual courses}

As mentioned earlier, some courses in computer science are difficult. For example, UML and .net courses will be abstract for students to comprehend if they are explained by teachers in English, and thus, the bilingual teaching difficulty becomes bigger and students often tend to lose interest, and finally the teaching effect is badly affected. For non-software students, C++ language is also such a course.

Therefore, the courses, such as $C$ Programming, Java Programming, and $S Q L$ Server Database, which are easy to understand and have orderly contents and regularity, can be chosen for the bilingual teaching. $C$ Programming is a classical process-oriented programming language, which is a rudimental language of programming algorithm and ideas; Java Programming is an object-oriented programming language in which $\mathrm{C}++$ is simplified and its complex composition is abandoned. The two languages, paying attention to an explanation to grammar rules, programming structure and ideas, can be used as rudimental languages for computer and non-computer majors. In SQL Server Database, the concept, design and application of database are studied. Therefore, SQL Server Database is practical obviously, which a necessary part of Microsoft MCDBA test and requires students to answer questions in English in the exam. For this reason, SQL Server Database, used as a bilingual course, is easy to stimulate students' interest in learning. $\mathrm{C}++$ Programming, because of its complete system, rigorous logic, abstractness, complex pointer, and multi-inheritance structure, can be used as a bilingual course for software majors, but is not suitable for non-software majors.

\subsection{Fully mobilizing students' learning enthusiasm with MOOC and flipped classroom}

Students are the main bodies of learning, and the bilingual course construction will lose direction and motivation if there are no students' participation and recognition. In today's high-speed development of the mobile Internet and the development of the modern education theory and education resources, giving full play to the active learning of students becomes a reality. Through guiding students to learn the quality videos in the related courses of Chinese MOOC University and paying more attention to the top university MOOC courses of the world, students' interest in learning is easy to be stimulated, especially the interest in the bilingual teaching. Subsequently, students can be better 
promoted to actively join the classroom teaching and play their subjective initiative through flipped classroom, etc. In the teaching, it is necessary to emphasize and train students' programming ability, play the collective wisdom, carry out team work, and stimulate the subject consciousness and enthusiasm for learning according to the requirements of project practices.

\subsection{Applying step-by-step teaching model and fitting the English proficiency of higher vocational students}

The problems such as low English competence, poor listening skill, a few vocabularies, and slow English reading speed of higher vocational students must be fully realized, but some students slack off gradually after they begin to study in a higher vocational college so that their actual English proficiency declines gradually and a direct negative impact on teaching is caused. Thus, teachers are required to apply a step-by-step teaching model, so as to instruct students from term's guidance to cross-penetration and gradual depth. In the cross-penetration phase, Chinese is used as the main teaching language, aided by English-English is better used more frequently in the teaching step by step. A whole semester is divided into four phases and then the targeted percentage of the teaching in English at the end of each phase is set to $5 \%, 15 \%, 30 \%$, and $40-45 \%$, respectively; after students get through the course adaptive phase, the percentage of the teaching in English can increase each weak according to chapters. In this way, the smooth transition of the students' competence is taken into consideration, and also the due teaching effect of the bilingual teaching is guaranteed.

\subsection{Choosing the "combination of production and learning" training materials as practice materials and improving the competitiveness of higher vocational students at workplace}

In terms of bilingual teaching materials, a teaching material system, integrating major teaching materials, practice materials, and reference books together, is used. In practice, practice materials play a very important role in students. Practice materials are guided by cases and usually compiled according to students' future jobs. Therefore, the employment-oriented and production-learning combined Chinese teaching materials, which are compiled by the current IT training institutions, must be applied, so as to lay an emphasis on practicality, availability, and advancement, and ultimately improve the competitiveness of higher vocational students at workplace.

\section{Conclusion}

In the process of bilingual teaching, all kinds of difficulties have emerged, but abandoning it halfway should never happen, because active aggressiveness and constant exploration for the ways of solving the problems are required. The importance and urgency of applying bilingual teaching in computer programming courses must be realized for promoting students to get a good command of the core means of the academic forelands, and simultaneously the work of several generations for the construction of bilingual courses is necessarily emphasized. Bilingual course, from "establishment" to "reconstruction" and "steady development", needs students, teachers, and colleges to make efforts and tries together. 


\section{References}

[1] Jiangtao GENG,Zanfu XIE \& Xiaoyun MO, Practice on Bilingual Education and Exam Reform of Vocational Computer Programming [J]. International Journal of Technology Management, 2014 No.11: 51-53.

[2] Jiangtao GENG, Zanfu XIE, Xiao-yun MO. Research and Practice of the Programming Language Examination Reform Valuing Competency in Higher Vocational Colleges [J]. Science and Wealth 2014 (11): 425-426.
[3] Xinxin WU, Xiaoqing YAN. Cold Consideration on the Bilingual Teaching in Colleges and Universities [J]. Journal of Ningbo University, 2010 (5): 117-120.

[4] Ying-jun ZHAO, Shubai LIANG. Re-examine the Dilemmas of the Bilingual Teaching in Colleges and Universities [EB/OL]. Beijing: China Science and Technology Papers Online, 04/29/2006. http://www.paper.edu.cn/releasepaper/conte nt/200604-430. 